\title{
Inactivation of Porphyromonas gingivalis by Low-Temperature Atmospheric Pressure Plasma
}

\author{
Arwa Mahasneh, ${ }^{1}$ Michele Darby, ${ }^{2}$ Susan L. Tolle, ${ }^{2}$ Wayne Hynes, ${ }^{3}$ \\ Mounir Laroussi, ${ }^{2,4}$ \& Erdinc Karakas ${ }^{4}$ \\ ${ }^{1}$ Department of Applied Dental Sciences, Faculty of Applied Medical Sciences, Jordan University \\ of Science and Technology, Irbid, Jordan; ${ }^{2}$ Gene W. Hirschfeld School of Dental Hygiene, Old \\ Dominion University, Norfolk, Virginia; ${ }^{3}$ Department of Biological Sciences, Old Dominion \\ University, Norfolk, Virginia; ${ }^{4}$ Laser and Plasma Engineering Institute, Department of Electrical \\ and Computer Engineering, Old Dominion University, Norfolk, Virginia

\begin{abstract}
Corresponding authors: Michele Darby, Michele Darby Eminent Scholar, University Professor, Chair of Gene W. Hirschfeld folk, VA 23529-0266; Tel.: (757) 683-3595; Fax: (757) 683-5283; whynes@odu.edu. Mounir Laroussi, Professor, Director, Laser \& Plasma Engineering Institute (LPEI), Electrical \& Computer Engineering Department, Old Dominion University, 231 Kaufman Hall, Norfolk, VA 23529; Tel.: 757-683-6369; Fax: 757-683-3220; mlarouss@odu.edu.
\end{abstract} \\ School of Dental Hygiene, Old Dominion University, Health Sciences Bldg, rm 2001, 4608 Hampton Blvd, Norfolk, VA \\ 23529-0499. Wayne Hynes, Ph.D., Professor \& Chair, Department of Biological Sciences, Old Dominion University, Nor-
}

\begin{abstract}
The biomedical application of low-temperature atmospheric pressure plasma (LTAPP) is a collaborative interest for engineering, medical, dental, and biological researchers. This laboratory study tested whether LTAPP can limit the growth of Porphyromonas gingivalis, a periodontal pathogen strongly associated with periodontal disease, disease progression, and refractory periodontitis. This proof of principle laboratory study of LTAPP's effects on $P$. gingivalis is an initial step in the development of a new nonsurgical periodontal therapy that could be used by dentists and dental hygienists. After pilot trials, the study consisted of 24 agar plate samples of $P$. gingivalis; 20 samples were exposed to LTAPP at 5, 7, 9, and 11 minutes and 4 control samples were exposed to helium gas only. Immediately after exposures, the samples were incubated anaerobically for 72 hours at $37^{\circ} \mathrm{C}$. After 72 hours, zones of inhibition were measured. After 5, 7, 9, and 11 minutes of exposure times, results revealed a statistically significant difference in the inactivation effect of the LTAPP on $P$. gingivalis compared with control bacteria that was not exposed, as measured by zone of inhibition $(\mathrm{cm})(P<0.0001)$. Differences in the inactivation effects were significant for each pair of consecutive time points: 5 minutes versus 7 minutes, 7 minutes versus 9 minutes, and 9 minutes versus 11 minutes $(P=$ $0.0360,0.0009$, and $<0.0001$, respectively). LTAPP has a significant dose-related inactivation effect on $P$. gingivalis, as measured by zone of inhibition. These findings advance the national dental hygiene research agenda by validating emerging strategies and technologies that might improve the effectiveness of the dental hygienist in periodontal disease management and by applying emerging science to the nonsurgical treatment and control of periodontal disease.
\end{abstract}

KEY WORDS: low temperature atmospheric pressure plasma, Porphyromonas gingivalis, periodontal disease, plasma pencil, zone of inhibition

\section{INTRODUCTION}

Porphyromonas gingivalis is a gram-negative, nonmotile, pleomorphic rod obligate an- 
aerobe. An aggressive periodontal pathogen, $P$. gingivalis can invade soft tissues. Fimbriae facilitate its adhesion to different surfaces and a capsule protects it against phagocytosis by the human immune system. P. gingivalis produces hemolysin, an enzyme that lyses red blood cells, and collagenase, an enzyme that destroys collagen fibers in host periodontal tissues. In addition, $P$. gingivalis inhibits the migration of polymorphonuclear leukocytes across the epithelial barrier and affects the production or the degradation of cytokines by mammalian cells causing tissue and bone loss in chronic periodontal inflammation.

Socransky et al ${ }^{1}$ analyzed more than 13,000 plaque samples using DNA hybridization methodology to search for 40 subgingival microorganisms associated with periodontal diseases. This work resulted in defined "complexes" of periodontal pathogens based on degrees of pathogenicity. ${ }^{1,2}$ P. gingivalis, Tannerella forsythensis, and Treponema denticola define the red complex bacteria, that is, those associated with periodontal pocketing and clinical attachment loss, which are the main parameters of destructive periodontal diseases. High numbers of $P$. gingivalis are found in chronic periodontitis and in active periodontal sites compared with inactive sites. Furthermore, $P$. gingivalis, along with $A$. actinomycetemcomitans, is one of the most significant microorganisms associated with localized aggressive periodontitis and is the dominant bacterial genus in periodontal abscesses. Also, P. gingivalis have been found in peri-implantitis with other pathogens. The proliferation of $P$. gingivalis is triggered by byproducts from other microorganisms such as succinate from Capnocytophaga ochraceus and protoheme from Campylobacter rectus. Moreover, breaking down the host hemoglobin results in hemin, which is used by $P$. gingivalis as a nutrient, hence its growth on lysed blood agar. ${ }^{2}$

Conventional methods of controlling and treating periodontal diseases target pathogens using mechanical procedures (scaling and root debridement) and chemotherapeutic agents (systemically or locally delivered antibiotics and antimicrobial agents). ${ }^{2}$ These interventions fail to achieve long-term control of periodontal pathogens. The purpose of this laboratory study was to determine the potential of low-temperature atmospheric pressure plasma (LTAPP) as a novel approach to inactivate $P$. gingivalis, a pathogen highly associated with chronic periodontal disease, localized aggressive periodontitis, and periodontal abscesses. $P$. gingivalis was studied because of its status as a red complex microorganism and its capability to invade periodontal tissue. This foundational work targeted LTAPP's potential as an intraoral intervention to prevent and control periodontal diseases.

\section{A. A. Significance of the Problem}

Most periodontal disease interventions target the management of microbial etiology. Daily removal of plaque biofilm, scaling, and root debridement using hand-activated and mechanized instruments ineffectively decrease most pathogens over the long term. Research consistently shows that after these interventions, periodontal pathogens cannot be completely eliminated. ${ }^{3,4}$ Mechanical procedures are supplemented with chemotherapeutic agents to further reduce the bacterial load and inhibit bacterial growth. Intraoral 
sites that fail to respond to these traditional interventions may be treated with systemically administered antibiotics. However, negative outcomes from systemic antibiotics include superinfections from opportunistic bacteria, development of resistant bacterial strains, adverse interactions with other medications, high cost of medications, and poor patient compliance. Local subgingival administration of antibiotics or antimicrobial agents also have been applied directly into periodontal pockets. ${ }^{5}$

Nevertheless, considering the minimal inhibition concentration values of the different chemotherapeutic agents required to control bacterial growth, in addition to the prolonged level of antibiotic in the gingival fluid needed for efficacy, elimination of bacterial biofilm is not achievable using chemotherapeutic agents alone or in conjunction with scaling and root debridement. ${ }^{6}$ To control or eradicate periodontal disease, therapy that does not use antibiotics is desirable. ${ }^{2}$ If LTAPP can eradicate $P$. gingivalis in vitro, then it may lead to an effective, efficient, and cost-effective approach to disinfect periodontal pockets and prevent the progression of periodontal disease.

LTAPP has lethal and inactivation potential against some microorganisms, including Escherichia coli, Geobacillus stearothermophilus, Staphylococcus aureus, Bacillus atrophaeu, Micrococcus luteus, and Bacillus cereus. ${ }^{7,8}$ This proof of principle laboratory study of LTAPP's effects on P. gingivalis is an initial step in the development of a new, nonsurgical, periodontal therapy method that could be used by the dental hygienist.

\section{REVIEW OF THE LITERATURE}

\section{A. Biomedical Application of LTAPP}

Outcomes from the application of LTAPP on various microorganisms provide the theoretical basis for this study. The lethal effects of LTAPP on gram-negative E. coli and gram-positive Bacillus subtilis have been tested by Laroussi et al. ${ }^{9}$ Results showed that LTAPP has a lethal effect on both $B$. subtilis and E. coli.

Researchers proposed that reactive oxygen species (ROS), reactive nitrogen species (RNS), and charged particles generated by LTAPP play dominant roles in the inactivation of cells. For example, to explain the reasons behind the cell structure damage of $E$. coli, the researchers proposed an electrophysical processes, that is, the plasma produces charged particles that accumulate on the outer cell surface and cause damage. ${ }^{9}$ The lethal potency of the plasma was influenced by the tensile strength, shape, and structure of the outer shell of the bacterial cell. Destruction in the cell of gram-negative bacteria could be due to the electrostatic disruption of the outer cell membrane. This electrophysical process is not effective on the more robust gram-positive bacterial cell wall because gram-positive bacteria do not have an outer membrane, but possess a thicker peptidoglycan, giving them greater strength and rigidity.

\section{B. Application of LTAPP in Sterilization}

Lee et $\mathrm{al}^{10}$ tested the sterilization effects of atmospheric pressure cold plasma (APCP) 
(synonymous with LTAPP) and its use in the clinical setting. E. coli, S. aureus, Saccharomyces cerevisiae, and $B$. subtilis were exposed to helium/oxygen plasma for different periods of time. The time required to achieve $10 \%$ reduction of the original numbers of the microorganism (at the specific plasma treatment conditions) was called the death value. After exposure to APCP, the samples of microorganisms were examined under the electron microscope. Death values were calculated at exposures of $18 \mathrm{sec}, 19 \mathrm{sec}$, 1 minute $55 \mathrm{sec}$, and 14 minutes for E. coli, S. aureus, S. cerevisiae, and B. subtilis, respectively. Inactivation of all the tested microorganisms occurred. Findings suggest that APCP using helium and oxygen produces oxygen radicals that penetrate the cell membrane of the microorganisms, ending in subsequent chemical reactions and cell death. ${ }^{10}$

Venezia et $\mathrm{al}^{8}$ investigated the sterilization effects of LTAPP on bacteria, spores, viruses, bacteriophages, and fungi. The microorganism samples were exposed to a plasma flow cycle for 10 minutes. Then the samples were cultured to quantify the microorganisms and derive the spore survival curves from the number of bacteria. Results showed a reduction in the viability of all microorganisms after 10 minutes of exposure to LTAPP. In addition, the primary destruction and damage occurred in the bacterial cell structures, as shown by electron microscopy: plasma caused distortion and destruction of the cell membrane.

\section{Porphyromonas gingivalis}

\section{Antibiotics and $P$. gingivalis}

Eick et $\mathrm{al}^{6}$ tested the differences in the efficacy of antibiotics against 3 periodontal pathogens grown in artificial biofilms. Those with a single species were established with artificial saliva and one of the following bacterial strains: Actinobacillus actinomycetemcomitans Y4, P. gingivalis American Type Culture Collection (ATCC) 33277, and Streptococcus constellatus 384b. The tested antibiotics included clindamycin, doxycycline, metronidazole, and moxifloxacin. The efficacy of antibiotics to the bacteria was specified using concentrations up to 100 -fold minimum inhibitory concentrations to the bacteria over 48 hours. Electron photographs were taken using a scanning electron microscope. A. actinomycetemcomitans Y4 and S. constellatus $384 \mathrm{~b}$ formed thick biofilms with many bacteria clearly attached. P. gingivalis ATCC 33277 formed a thinner layer of biofilm. After adding clindamycin, electron micrographs showed minor deviations of the biofilm matrix, and the number of the bacteria had not decreased. Doxycycline changed the structure of the biofilm, and fewer bacteria were visible compared to the control. Moxifloxacin showed the most prominent results, with the matrix partially departed and the number of the bacteria significantly reduced. Results showed that metronidazole had no effect on P. gingivalis ATCC 33277. Among the tested antibiotics, moxifloxacin was the most efficient. The researchers concluded that complete killing of bacteria by antibiotics alone was not achievable considering the minimum inhibitory concentrations and the level of antibiotic in the gingival fluid. ${ }^{6}$ Findings support the need for better approaches to periodontal pathogen control. 


\section{Photosensitization of $P$. gingivalis}

Photodynamic therapy (PDT) using helium-neon laser irradiation is a well-known phototoxic method to kill periodontal pathogens such as $P$. gingivalis. Using PDT requires a light source and photosensitizer set close to the target microorganisms. Matevski et $\mathrm{al}^{3}$ investigated the potential of the red-filtered xenon lamp, a conventional light source, in combination with toluidine blue $\mathrm{O}$, a synthesized chemical photosensitizer that can absorb red laser light to kill $P$. gingivalis. Researchers compared the effectiveness of this treatment to that of a helium-neon laser. Treatment with a helium-neon laser resulted in bacterial kill of $2.43 \pm 0.39 \operatorname{logs}$, whereas using the xenon lamp resulted in bacterial kill of $3.34 \pm 0.24 \operatorname{logs}$, an increase of nearly 10-fold. Findings suggest that PDT using conventional light is at least as effective as laser-induced treatment. Moreover, increasing the light intensity and the dose resulted in higher $P$. gingivalis kills. ${ }^{3}$

\section{Visible Light Irradiation Effects on P. gingivalis}

Fukui et $\mathrm{al}^{4}$ investigated the kill and inhibition potential of different visible light wavelengths on $P$. gingivalis, even in the absence of photosensitizers, using the Okazaki large spectrograph. $P$. gingivalis ATCC 33277 colonies were exposed to monochromatic light using the Okazaki large spectrograph; the examined wavelengths ranged from 400 to $700 \mathrm{~nm}$. A monochromatic, 405-nm light-emitting device was used on the 24-hour bacterial culture that was grown in supplemental brain-heart infusion broth. After light exposure, the samples were incubated in an anaerobic chamber. Bacterial growth was measured at 12- and 24-hour intervals. Significant inhibition of $P$. gingivalis occurred at $400 \mathrm{~nm}$ and $410 \mathrm{~nm}$; using a wavelength of $430 \mathrm{~nm}$ or longer produced no significant inhibition. Increasing exposure time resulted in increased bacterial inhibition under constant output power; increasing the output power resulted in an increased inhibitory effect of irradiation on $P$. gingivalis with constant exposure.

\section{METHODS AND MATERIALS}

\section{A. Research Design}

For each trial, the experimental groups consisted of 20 inoculated agar plates exposed to LTAPP; controls consisted of 4 inoculated plates exposed to helium only (see Table 1). Exposed and unexposed samples of $P$. gingivalis were incubated in the anaerobic chamber. After incubation, each agar plate was held a few centimeters above a nonreflecting background. While under good light, the size of the zone of inhibition on the upper surface of agar was measured using a Boley gauge. ${ }^{11}$

\section{Procedures, Materials, and Data Collection Instruments}

Standard microbiology laboratory procedures for growing bacteria in broth, plating, and 
TABLE 1. Factorial Design $(2 \times 5)$ with Zone of Inhibition as the Dependent Variable

\begin{tabular}{|c|c|c|c|c|c|}
\hline & Bacteria & $\begin{array}{c}\text { Independent } \\
\text { variables } \\
\text { (exposure } \\
\text { times) }\end{array}$ & $\begin{array}{c}\text { Replicates } \\
\text { of each trial }\end{array}$ & $\begin{array}{c}\text { Total of } \\
\text { exposed } \\
\text { plates }\end{array}$ & $\begin{array}{c}\text { Dependent } \\
\text { variable } \\
\text { measure }\end{array}$ \\
\hline $\begin{array}{c}\text { Experimen- } \\
\text { tal (helium } \\
\text { LTAPP) }\end{array}$ & $\begin{array}{c}\text { Porphyromo- } \\
\text { nas gingivalis }\end{array}$ & $\begin{array}{c}5,7,9 \text {, and } 11 \\
\text { min }\end{array}$ & $\begin{array}{c}5 \text { per } \\
\text { exposure }\end{array}$ & 20 & $\begin{array}{c}\text { Zone of } \\
\text { inhibition }\end{array}$ \\
\hline $\begin{array}{c}\text { Control } \\
\text { (helium only) }\end{array}$ & $\begin{array}{c}\text { Porphyromo- } \\
\text { nas gingivalis }\end{array}$ & $\begin{array}{c}5,7,9 \text {, and } 11 \\
\text { min }\end{array}$ & $\begin{array}{c}1 \text { per } \\
\text { exposure }\end{array}$ & 4 & $\begin{array}{c}\text { Zone of } \\
\text { inhibition }\end{array}$ \\
\hline
\end{tabular}

LTAPP, low-temperature atmospheric pressure plasma.

incubating were followed. Sterile equipment and supplies were used to decrease risk of cross-contamination in the microbiology laboratory and anaerobic chamber. Before the actual trials, pilot experiments were performed to test the potential of LTAPP to kill or inhibit the growth of $P$. gingivalis. P. gingivalis strain 33277, commonly used in periodontal research, was purchased from the ATCC. An anaerobic chamber served as the environment for inoculating and growing $P$. gingivalis on blood tryptic soy sheep blood agar plates and in tryptic soy broth (TSB). Old Dominion University's Department of Biological Sciences' Microbiology Laboratory and the School of Dental Hygiene's Anaerobic Chamber Laboratory were used for all microbiology procedures. Helium LTAPP and control exposures occurred at the Plasma Engineering Institute's Department of Electrical and Computer Engineering at the same university. To prevent cross-contamination, at the start and end of each procedure, working surfaces were sprayed with $5.25 \%$ sodium hypochlorite and allowed to remain wet for 10 minutes, then wiped dry.

\section{Microbiological Procedures for Subculturing the P. gingivalis Performed in the Anaerobic Chamber}

TSB sheep blood agar plates were prepared in the microbiology laboratory 1 to 2 days before LTAPP treatment. TSB sheep blood agar plates were marked with an $X$ in the center to serve as the plasma target. Each plate was labeled with the date of plating, name of bacteria, treatment, and exposure time. Prepared blood agar plates were carried to the anaerobic chamber. $P$. gingivalis was inoculated into $5.0 \mathrm{~mL}$ of TSB nutrient broth. A TSB sheep blood agar plate was inoculated with $P$. gingivalis and incubated for 48 hours at $37^{\circ} \mathrm{C}$ for visible bacterial growth. A new plate was made weekly to keep the bacteria viable. A sterilized bacterial loop was swiped across a $P$. gingivalis colony on the old plate, using a T-streak technique, to inoculate the new plate. The TSB was made; 5.0 $\mathrm{mL}$ of TSB was inoculated with $P$. gingivalis and incubated for 48 hours at $37^{\circ} \mathrm{C}$ before using it on the day of exposure. On the days of exposure, TSB agar plates were inoculated as a lawn with $P$. gingivalis using a sterile cotton swab. Plates were taken out of the anaerobic chamber and placed in portable anaerobic jars for transport to the plasma 


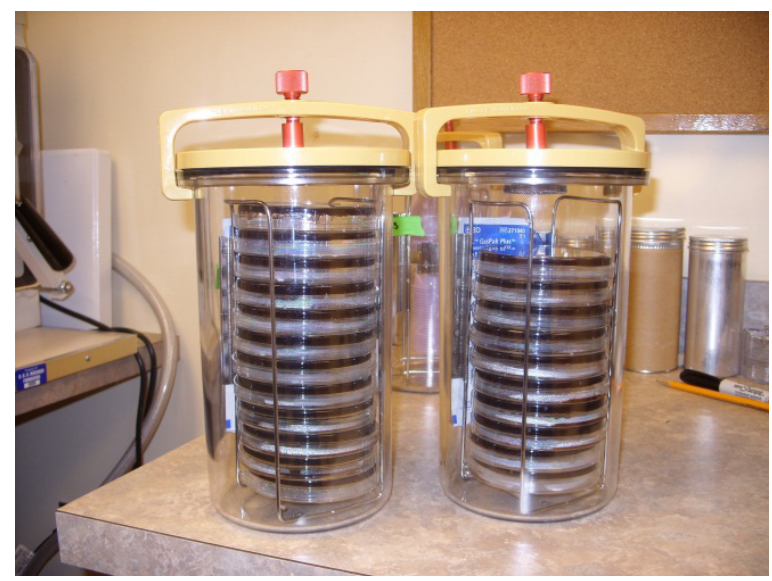

FIGURE 1. Tryptic soy broth sheep agar plates inoculated with Porphyromonas gingivalis in the portable anaerobic jars.

laboratory (see Fig. 1). To reduce the oxygen in the jars, a palladium catalyst system was activated to keep the environment in the jars anaerobic. ${ }^{12}$

\section{Helium LTAPP Exposure Procedures in the Plasma Laboratory}

Plasma exposures were performed using the LTAPP pencil, designed by Laroussi, that generates a plume using helium as a working gas and nano-second order high-voltage pulses as a power source, ${ }^{12}$ delivering pulses of plasma to a target. Within a factorial design, LTAPP exposure times of 5, 7, 9, and 11 minutes served as specific independent variables (see Table 1). For reliability, each exposure was repeated 5 times. The bacteria's zone of inhibition after exposure (or no exposure) to the helium LTAPP and incubation in the anaerobic chamber was the dependent variable. Settings used during helium LTAPP exposure include voltage of $8 \mathrm{kV}$, frequency of $5 \mathrm{kHz}$, pulse width of 500 nsec, and a flow rate of $5 \mathrm{~L} / \mathrm{min}$. The experimental and the control agar plates were taken out of the jars and placed on the countertop. For each agar plate, the plasma pencil tip was aimed at the center (marked with an $X$ ) and adjusted to the height of the wall of the Petri dish $(1.3 \mathrm{~cm})$ (see Fig. 2). Each plate was treated for the assigned exposure time and then covered and placed on the countertop. After all plates were treated, they were stacked into the portable anaerobic jar and transported back to the anaerobic chamber, where they were incubated for 72 hours at $37^{\circ} \mathrm{C}$.

\section{Microbiology Procedures After LTAPP Treatment}

After 72 hours of incubation, the control and the experimental plates were observed and zones of inhibition were measured (see Fig. 3). Once data were recorded, the plates were photographed using the same digital camera and settings and then taken to the microbi- 

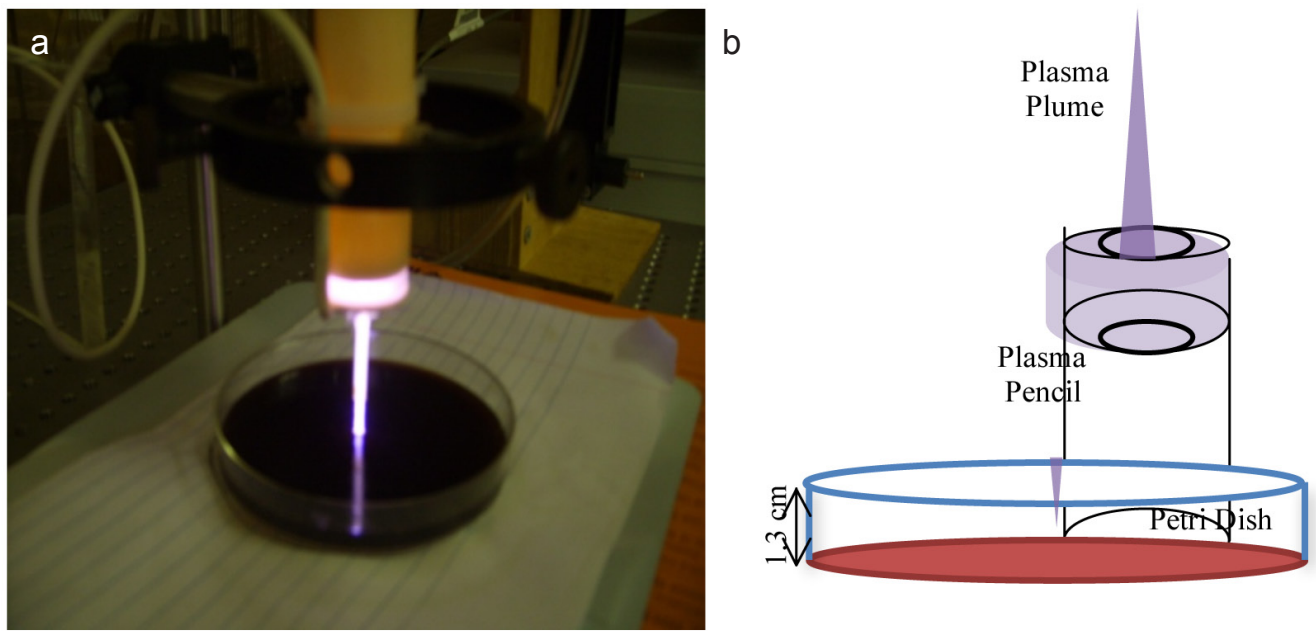

FIGURE 2. (a) Exposing tryptic soy broth sheep agar plates inoculated with Porphyromonas gingivalis to low-temperature atmospheric pressure plasma; (b) plasma pencil tip adjusted to the height of the Petri dish wall $(1.3 \mathrm{~cm})$.

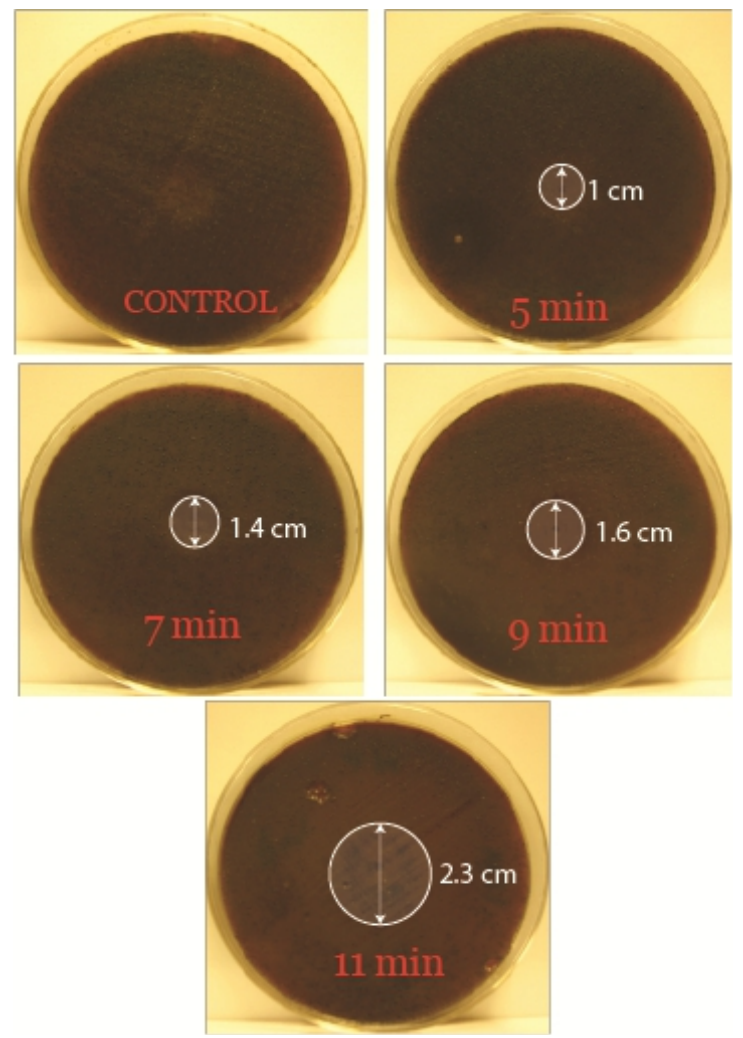

FIGURE 3. $P$. gingivalis-inoculated TSB sheep agar plates. Exposure times to the plasma and the inhibition zone diameters are labeled for each plate. 
ology laboratory for sterilization and disposal.

\section{B. Statistical Analysis}

For each trial within each exposure group, the mean and standard deviation of the size of the inhibition zones were calculated and compared between the experimental and the control groups. Using the Proc general linear model procedure in SAS software program, version 9.2 (SAS, Inc, Cary, NC), a mixed effects model was fitted to the data. In this model, each plate was considered a random effect. The model also accounts for repeated measures that were taken over time. Significant differences between measurements at different time points were calculated using analysis of variance and the contrast statement (statement in the SAS software program used to compare means at different time points). Data were ratio scaled, which further supported the use of parametric procedures.

\section{RESULTS}

Results revealed a statistically significant difference in the inactivation of $P$. gingivalis by the LTAPP after 5, 7, 9, and 11 minutes of exposure compared with the control bacteria that were not exposed, as measured by zone of inhibition $(\mathrm{cm})(P<0.0001)$. Control plates showed no killing, that is, no zone of the inhibition (see Table 2). The differences in the bacteria inactivation effects are significant for each pair of consecutive time points: 5 minutes versus 7 minutes, 7 minutes versus 9 minutes, and 9 minutes versus 11 minutes $(P=0.0360,0.0009$, and $<0.0001$, respectively) (see Table 3$)$. The mean zones of inhibition increase as the exposure time increases, suggesting that LTAPP has a dose effect on inactivation of $P$. gingivalis: the greater the exposure time, the larger the zone of inhibition. Increasing the exposure time from 5 to 7 minutes, 7 to 9 minutes, and 9 to 11 minutes resulted in increasing the zone of inhibition by $9.5 \%, 14.7 \%$, and $18.6 \%$, respectively. However, some plates showed no total inhibition of the bacteria in the marked areas.

\section{DISCUSSION}

Outcomes suggest that LTAPP inhibits growth of $P$. gingivalis ATCC strain 33277, as measured by zones of inhibition. In this study, inactivation of $P$. gingivalis was most likely caused by charged particles and oxygen radicals. Charged particles play a significant role in damaging the outer membrane of bacteria. ${ }^{13}$ Mendis et al ${ }^{14}$ demonstrated that the accumulation of charged particles, produced from plasma, on the outer surface of the bacterial cell membrane will produce electrostatic forces that could overcome the tensile strength of the cell membrane and cause its rupture. This process is more likely to happen for gram-negative bacteria with an irregular cell membrane, such as $P$. gingivalis, than with gram-positive bacteria. These irregularities serve as small radii of curvature that produce localized high outward electrostatic forces that cause cell rupture. Reac- 

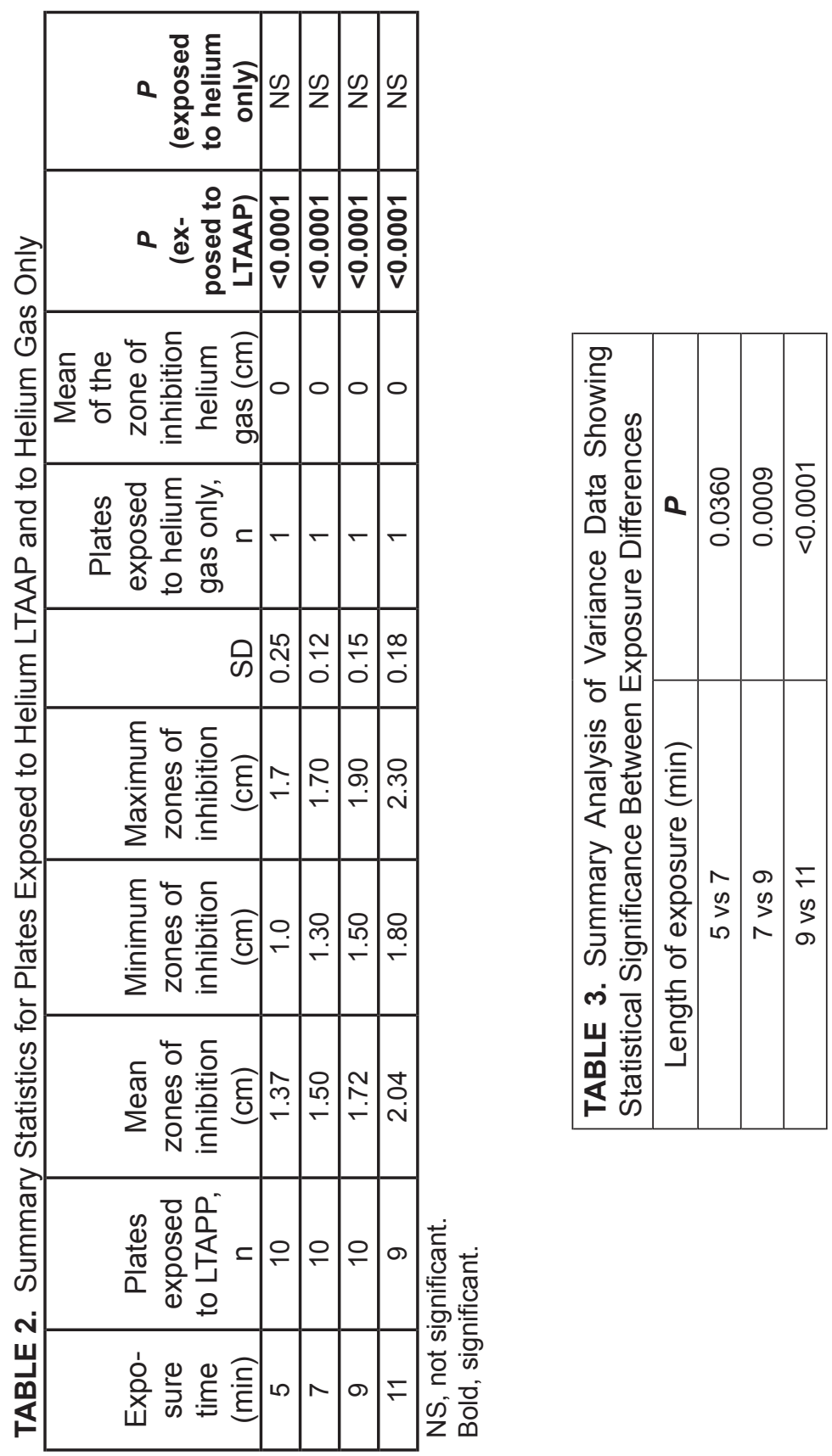
tive species are produced during high-pressure nonequilibrium plasma discharges. Air plasmas are good sources of reactive oxygen-based species $\left(\mathrm{O}, \mathrm{O}_{2}, \mathrm{O}_{3}\right.$, and $\left.\mathrm{OH}\right)$ and nitrogen-based species $\left(\mathrm{NO}, \mathrm{NO}_{2}\right)$. These reactive species affect the outer structure of cells by methods of oxidation and disturb its function, leading directly or indirectly to the death of the cell.

Given the diameter of the LTAPP plume $(3 \mathrm{~mm})$, there is a maximum point beyond which inhibition does not go (about $2.1 \mathrm{~cm}$ ). This observed behavior of the plume is considered an advantage in medical and dental applications of LTAPP, where localized, targeted treatments are preferred. However, the exposure time at which the inactivation of $P$. gingivalis by helium LTAPP took place $(5,7,9$, and 11 minutes), was longer than that needed to inactivate Streptococcus mutans (gram-positive bacteria; 60, 120, 180, 300 seconds) (Lemaster M. Effects of low temperature atmospheric pressure plasma on Streptococcus mutans. Unpublished research, 2008). The literature suggests that different exposure times are needed to inactivate various microorganisms. In the Lee et al ${ }^{10}$ study, $10 \%$ reduction in the original number of $E$. coli (gram-negative bacteria), $S$. aureus (gram-positive bacteria), S. cerevisiae (yeast), and B. subtilis (bacterial endospores) was achieved after $18 \mathrm{sec}, 19 \mathrm{sec}, 1$ minute $55 \mathrm{sec}$, and 14 minutes, respectively, of exposure to APCP.

Findings from this study revealed that helium LTAPP has a dose effect on the zone of inhibition of $P$. gingivalis, whereby increasing the exposure time resulted in an increase in the diameter of the inhibition zone. Similarly, Fukui et $\mathrm{al}^{4}$ concluded that increasing the time of exposure to visible light irradiation (without using photosensitizers) under constant output power $\left(50 \mathrm{~mW} / \mathrm{cm}^{2}\right)$ resulted in an increase in the inhibitory effects on $P$. gingivalis. Furthermore, findings of Matevski et al ${ }^{3}$ suggest that using conventional light is at least as effective on $P$. gingivalis inactivation as laser-induced treatment. Also, increasing the light intensity and the dose yielded greater killing of $P$. gingivalis. ${ }^{3}$ In the current study, pilot testing revealed that using a voltage of $8 \mathrm{kV}$ resulted in more killing than using a voltage of 5 or $5.5 \mathrm{kV}$.

As already discussed, inactivation of $P$. gingivalis might be attributed to the fact that plasma generates ROS, which, in high enough doses, attack the cell membrane of the microorganisms and disturb their function, leading to cell death. ${ }^{11,13,15}$ It should be noted that PDT also suppresses microorganisms by ROS.,16 In periodontal inflammation, polymorphonuclear leukocytes (PMNLs) serve as the initial host defense against periodontal pathogens including $P$. gingivalis. After stimulation by bacterial antigens and during phagocytosis, PMNLs produce reactive oxygen species (ROS) such as superoxide $\left(\mathrm{O}_{2}^{-}\right)$, hydrogen peroxide $\left(\mathrm{H}_{2} \mathrm{O}_{2}\right)$, single oxygen $\left(\mathrm{O}_{2}\right)$, and hydroxy radicals $(\mathrm{OH})$. ROS are the main elements of bactericidal activity of PMNLs. ${ }^{17-19}$ However, it was found that many anaerobic bacteria produce enzymes, such as superoxide dismutase, catalase, and peroxide, that neutralize these toxic reactive products. ${ }^{17,20}$

$P$. gingivalis virulence may be related to its ability to produce a specific superoxide dismutase enzyme that neutralizes the PMNL toxic products of oxidative metabolism. ${ }^{17,21}$ This explanation might be the reason that 5, 7, 9, and 11 minutes were needed to 
achieve observed inhibition in $P$. gingivalis growth using LTAPP, which also generates oxygen radicals.

The morphological structure of $P$. gingivalis might be another possible explanation for the relatively long time required to inactivate $P$. gingivalis. $P$. gingivalis is a gram-negative, non-spore-forming, anaerobic bacteria that more closely relates to gram-positive bacteria than other gram-negative bacteria. ${ }^{22} P$. gingivalis has an outer membrane, a peptidoglycan layer, and a cytoplasmic membrane. ${ }^{21}$ Bachrach et $\mathrm{al}^{23}$ believe that the unique lipopolysaccharide structure of $P$. gingivalis might contribute to its resistance to antimicrobial peptides. Also, Altman et $\mathrm{al}^{24}$ tested the antibacterial activity of the amphibian-derived K4-S4(1-15) antimicrobial peptide against oral pathogens associated with dental caries and periodontitis and compared it with the activities of the human-derived antimicrobial peptides LL-37 and dhvar4a. The results revealed that $P$. gingivalis ATCC 33277 and $P$. gingivalis W50 were the most resistant strains to the 3 tested peptides among the tested bacteria (Actinomyces viscosus, Lactobacillus paracasei, S. mutans, Streptococcus sobrinus, Fusobacterium nucleatum, A. actinomycetemcomitans, and E. coli). ${ }^{24}$

Several factors were considered in the protocol and during interpretation of the results. Helium LTAPP was tested in vitro on $P$. gingivalis and not on human subjects; therefore, one cannot conclude that helium LTAPP is an effective inactivation method of $P$. gingivalis-infected periodontal pockets at this time. LTAPP is a new technology that has the potential to become an effective method to eradicate pathogenic microorganisms in dental patients.

Studies are needed to investigate the inactivation effects of LTAPP on P. gingivalis, the mechanism of the inactivation, and the morphological changes that might occur in the bacterial cell resulting in cell death. This study did not explore either structural changes at the cellular level or mechanism of inactivation. Future studies are needed to investigate LTAPP's mechanism of inactivation on $P$. gingivalis and to explore and identify the morphological and the structural changes in $P$. gingivalis due to LTAPP exposure, using other measures such as transmission electron microscopy or scanning electron microscopy. Studies should be conducted using different gases and mixed gases, voltages, and LTAPP delivery devices to establish more effective protocols to inactivate $P$. gingivalis. $P$. gingivalis thrives in an inflammatory environment in the presence of oxygen radicals, which may also explain why $P$. gingivalis is not easily inhibited by LTAPP exposure. Research suggests that oxygen radicals produced by PMNLs during the periodontal inflammatory process may damage some periodontal pathogens and the PMNLs themselves and may correlate with the destruction of periodontal tissue. ${ }^{25}$ These concepts need laboratory and clinical research evidence if cold plasma is to be applied as a nonsurgical periodontal therapy.

\section{ACKNOWLEDGMENTS}

Special thanks to the American Dental Hygienists' Association's Institute for Oral Health for funding this research. 


\section{REFERENCES}

1. Socransky SS, Haffajee AD, Cugini MA, Smith C, Kent RL Jr. Microbial complexes in subgingival plaque. J Clin Periodontol. 1998;25:134-144.

2. Quirynen M, Teughels W, Kinder Haake S, Newman MG. Microbology of periodontal diseasees. In: Newman MG, Takei H, Perry Klokkkevold R, Carranza FA, eds. Carranza's Clinical Periodontology. 11th edition. St. Louis, MO: Sauders Elsevier; 2012:135-169.

3. Matevski D, Weersink R, Tenenbaum HC, Wilson B, Ellen RP, Leẻpine G. Lethal photosensitization of periodontal pathogens by a red-filtered xenon lamp in vitro. $\mathrm{J}$ Periodontal Res. 2003;38:428-435.

4. Fukui M, Yoshioka M, Satomura K, Nakanishi H, Nagayama M. Specific-wavelength visible light irradiation inhibits bacterial growth of Porphyromonas gingivalis. J Periodontal Res. 2008;43:174-178.

5. Santos S, Herrera D, Lopez E, O’Connor A, Gonzalez I, Sanz M. A randomized clinical trial on the short-term clinical and microbiological effects of the adjunctive use of a $0.05 \%$ chlorehexidine mouth rinse for patients in supportive periodontal care. J Clin Periodontol. 2004;31:45-51.

6. Eick S, Seltmann T, Pfister W. Efficacy of antibiotics to strains of periodontopathogenic bacteria within a single species biofilm: an in vitro study. J Clin Periodontol. 2004;31:376-383.

7. Yu QS, C Huang, Hsieh F-H, Huff H, Duan Y. Bacterial inactivation using a lowtemperature atmospheric plasma brush sustained with argon gas. J Biomed Mater Res B Appl Biomater. 2007;80:211-219.

8. Venezia RA, Orrico M, Houston E, Naumova YY. Lethal activity of nonthermal plasma sterilization. Infect Control Hosp Epidemiol. 2008;29:430-436.

9. Laroussi M, Mendis DA, Rosenberg M. Plasma interaction with microbes. New J Phys. 2003;5:41.1-41.10.

10. Lee K, Paek K-H, Ju W-T, Lee Y. Sterilization of bacteria, yeast, and bacterial endospores by atmospheric-pressure cold plasma using helium and oxygen. J Microbiol. 2006;44:269-275.

11. Turnidge JD, Bell JM, Antimicrobial susceptibility on solid media. In: Lorian V. Antibiotics in laboratory medicine. 5th edition. Philadelphia: Lippincott Williams \& Wilkins; 2005:30-51.

12. Laroussi M, X. Lu X. Room temperature atmospheric pressure plasma plume for biomedical applications. Appl Phys Lett. 2005;87:113902.

13. Laroussi M. Nonthermal decontamination of biological media by atmospheric-pressure plasmas: review, analysis, and prospects. IEEE Trans Plasma Sci. 2002;30:1409-1415. 
14. Mendis DA, Rosenberg M, Azam F. A note on the possible electrostatic disruption of bacteria. IEEE Trans Plasma Sci. 2000;28:1304-1306.

15. Laroussi M. Low temperature plasma-based sterilization: overview and state-ofthe-art. Plasma Process Polym. 2005;2:391-400.

16. Dougherty TJ, Gomer CJ, Henderson BW, Jori G, Kessel D, Korbelik M, Moan J, Peng Q. Photodynamic therapy. J Natl Cancer Inst. 1998;90:889-905.

17. Amano A, Ishimoto T, Tamagawa H, Shizukuishi S. Role of superoxide dismutase in resistance of Porphyromonas gingivalis to killing by polymorphonuclear leukocytes. Infect Immun. 1992;60:712-714.

18. Ritchie CS, Kinane DF. Nutrition, inflammation, and periodontal disease. Nutrition. 2003;19:475-476.

19. Mims CA, Nash A, Stephen J. The encounter with phagocytic cell and the microbe's answers. In: Mims CA. The Pathogenesis of Infectious Disease. Waltham, MA: Academic Press. 2001: 84-119.

20. Beaman L, Beaman BL. The role of oxygen and its derivatives in microbial pathogenesis and host defense. Ann Rev Microbiol. 1984;38:27-48.

21. Amano A, Tamagawa H, Takagaki T, Murakami Y, Shizukuishi S, Tsunemitsu A. Relationship between enzyme activities involved in oxygen metabolism and oxygen tolerance in black pigmented bacteroides. J Dent Res. 1998;67:1196-1199.

22. Porphyromonas. Cell structure and metabolism. Updated 6 August 2010 [cited 16 October 2009]. Available at: http://microbewiki.kenyon.edu/index.php/ Porphyromonas\#Cell_Structure_and_Metabolism.

23. Bachrach G, Altman H, Kolenbrander PE, Chalmers NI, Gabai-Gutner M, Mor A, Friedman M, Steinberg D. Resistance of Porphyromonas gingivalis ATCC 33277 to direct killing by antimicrobial peptides is protease independent. Antimicrob Agents Chemother. 2008;52:638-642.

24. Altman H, Steinberg D, Porat Y, Mor A, Fridman D, Friedman M, Bachrach G. In vitro assessment of antimicrobial peptides as potential agents against several oral bacteria. J Antimicrob Chemother. 2006;58:198-201.

25. Katsuragi H, Ohtake M, Saito K. Intracellular production and extracellular release of oxygen radicals by PMNs and oxidative stress on PMNs during phagocytosis of periodontopathic bacteria. Odontology. 2003;91(1):13-18. 